\title{
The Use of Supersulfated Cement(SSC)in Mass Concrete
}

\author{
Shu WANG ${ }^{1 *}$, Jing $\mathrm{WU}^{2}$, Xiong $\mathrm{WU}^{1}$, Wen $\mathrm{YANG}^{1}$ and Baoying $\mathrm{YU}^{1}$ \\ ${ }^{1}$ China Construction Ready Mixed Concrete Co. ,Ltd. ,Wuhan,430070) \\ ${ }^{2}$ Wuhan textile university,wuhan,430200)
}

\begin{abstract}
This paper isfocused on the use of Supersulfated Cement (SSC) in mass concrete. The physicalproperties and mechanicalproperty was tested. Contrast with the common cement, this paper studied the temperature rise of hydration and the heat of hydration to obtain the advantage of SSC, which will provide the basis for the use of SSC in mass concrete.The micro properties were tested through Scanning Electron Microscope (SEM). The test shows that the SSC shows better workingperformance than ordinary cement. The compressive strength of SSC under standard curing condition is higher than that under room curing condition. The compressive strength of SSC is increasing with time and the rate of increasing is decreasing. The temperature rise of hydration of SSC are lower than that of ordinary cement. Different with the ordinary cement, the main hydrated products of SSC areettringite and scalycalcium silicate hydrate.
\end{abstract}

\section{Introduction}

Supersulfated Cement (SCC) which is mainly produced by granulated blast furnace slag and using gypsum as sulfate exciting agent and clinker or lime as alkaline exciting agent is a kind of clinker-free cement, which is also been called as slag-gypsum cement andslag sulphated cement. The components proportion of SSC usually is $75 \% \sim 75 \% \mathrm{slag}, 10 \% \sim 20 \%$ of sulfate class (such as dihydrate gypsum and anhydrite, etc.) and 1\% 5\% content of alkaline elements (such as clinker, calcium hydroxide, etc.). With good properties and simple manufacturing technique and low cost, SSC is a kind of energy conservation and environmental friendly cement. Contrary to the ordinary cement, SSC has the advantage of lower heat of hydration ${ }^{[1]}$, control thealkali aggregate reaction (AAR) because of the higher content of granulated blast furnace slag that is useful to restrain $\mathrm{AAR}^{[2-3]}$ and good sulfate resistance.

As the application of SSC prevalent in European countries, the worldwide interest in the understanding and research of SSCis more and more strong.At present the sulfate cement has very good sales market, which has been applied into multiple fields, such as sewage treatment plant, pool, water concrete, industrial workshop floor mass concrete, concrete pile and other aspects.Resently the main research of SSC is focused on the use of industrial waste residue in SSC, the physical mechanics performance of SSC, which showed that SSC has

\footnotetext{
* Project number: CSCEC-2014-Z-34;51302195.
} 
lower strength in the early age but can overtake the strength of ordinary cement ${ }^{[4]}$. In ChinamingfanZhouetc. ${ }^{[5-6]}$ studied the principle of sulfate activating and alkaline activating and developed a kind ofspecial SSC cement using in base pavement, which has been used in the construction of several highways and works well.

The application of the SSC is still in research stage, which is not perfect. This study focused on using SSC in mass concrete.First by studying its physical properties, mechanical properties, this paper studied the feasibility of its application in the concrete.As the big volume and the lower surface thermal conductance of concrete, thereactionrate is very fast and main hydration process focuses in shorter time, which caused the rapid increasing of internal temperature and the largedifference between inside and outside temperatures. When the difference between inside and outside temperatures exceeds a certain limit, the concrete will crack which affects thequality of construction in the mass concrete construction $^{[7]}$. So it's a critical problem to control hydration heat temperature differencein the construction of mass concrete. Compared with the ordinary Portland cement, this paper studied the temperature rise of hydration and the heat of hydration of SSC and analysis the advantages of SSC, which will provides abasis for its further use in mass contrete. Themiro properties of SSC is also investigated to analysis its hydration products and reveals the hydrationmechanism.

\section{Materials and Experimental Process}

\subsection{Materials}

The homemade compoundactivator of SSC can stimulatetheactiveofmineral powder fully. Mineral powder used is consist with the requests of chinese standard -'Graining of blast furnace slag used for cement and concrete'(GB/T18046-2008). SSC is made by compoundactivator and mineral powderin a certainproportion. The ordinary Portland cement (OPA) P.O 42.5 and stair fly ash is used in this test.Chemicalcomponent of mineral powder, SSC, ordinary Portland cement and fly ash is listed is Table 1. River sand with 2.59 of finenessmodulus, 2.9 percent of mudcontent and good grading is consist with the medium sand requests. The gravel with 3.6 percentage of flat-elongatedparticles content, 7.5 percentage of crush index, 0.5 percent of mudcontent and good grading is consist with $5-20 \mathrm{~mm}$ grading requests. PC-5 waterreducingagent is used in the test.

TABLE 1 CHEMICAL COMPOSITIONS OF RAW MATERIALS, MASS/\%

\begin{tabular}{ccccccccccc}
\hline compositions & $\mathrm{Na}_{2} \mathrm{O}$ & $\mathrm{MgO}$ & $\mathrm{Al}_{2} \mathrm{O}_{3}$ & $\mathrm{SiO}_{2}$ & $\mathrm{P}_{2} \mathrm{O}_{5}$ & $\mathrm{SO}_{3}$ & $\mathrm{~K}_{2} \mathrm{O}$ & $\mathrm{CaO}$ & $\mathrm{Fe}_{2} \mathrm{O}_{3}$ & loss \\
\hline mineral powder & 0.297 & 6.705 & 14.500 & 32.320 & 0.032 & 2.810 & 0.661 & 40.230 & 0.985 & 1.460 \\
$\mathrm{SSC}$ & 0.240 & 5.382 & 11.629 & 25.811 & 0.339 & 12.238 & 0.572 & 41.251 & 0.991 & 1.574 \\
OPA & 0.083 & 1.360 & 5.406 & 20.250 & 0.112 & 3.962 & 1.120 & 63.090 & 3.243 & 1.374 \\
fly ash & 0.420 & 2.790 & 25.790 & 53.410 & 0.012 & 0.300 & 1.360 & 2.600 & 4.280 & 3.668 \\
\hline
\end{tabular}

\subsection{Experimental process}

The mix proportions of mortar are shown in Table 2.Different design of C30 and C50 was designed which is consist with thedesignregulations of mix ratio of ordinary concrete(JGJ55-2000). The $1 \times 1 \times 1 \mathrm{~m}^{3}$ was completed one time under environment of $35 \%$ $\mathrm{RH}$ and $38^{\circ} \mathrm{C}$ and threemetalprobes were pre-embeddedin the position of the center, 0.25 meters of the central line to the uppersurface of the concrete and the 0.75 meters of the central 
line to the uppersurface of the concrete for testingtemperature rise of hydration. The average temperature of the three testing results was the final results. Meanwhile the $100 \times 100 \times 100$ $\mathrm{mm}^{3}$ concrete specimens were prepared and cured (higher than $90 \% \mathrm{RH}$ and $20 \pm 1{ }^{\circ} \mathrm{C}$ ) for $48 \mathrm{~h}$, then demolded. After that, half of the specimens were cured under standard condition and the others were cured at room temperature. Compressive strengths of the mortars were determined at 3, 28, 56 days and one year in accordance with Chinese standard GB/T 17671-1999. The microstructure and hydration products were tested by scanning electron microscopy (SEM). The test samples were collected in the core of specimens after being broken and eliminated lager particles, and were soaked in anhydrous ethanol to terminate the hydration for microstructuraltests.

The hydration heat of SSC paste was tested by thermal conductivity type isothermal calorimeter. The heat of hydration and its rate of different system was tested within 72 hours. The water/cement $(\mathrm{w} / \mathrm{c})$ ratio is fixed 0.286 that is same the C50 concrete and the temperature is controled at $20{ }^{\circ} \mathrm{C}$. Raw material proportion is shown in table 3.

TABLE 2 MIX PROPORTION OF THECONCRETE(WT, \%)

\begin{tabular}{|c|c|c|c|c|c|c|c|c|}
\hline \multirow{2}{*}{ concrete } & \multirow{2}{*}{ designlevel } & \multicolumn{7}{|c|}{ mass $/ \mathrm{kg}$} \\
\hline & & \multicolumn{2}{|c|}{$\mathrm{SSC}$} & \multicolumn{2}{|c|}{ gravel } & sand & water & $\begin{array}{l}\text { water } \\
\text { reducer }\end{array}$ \\
\hline LSSC & $\mathrm{C} 30$ & \multicolumn{2}{|c|}{680} & \multicolumn{2}{|c|}{2212} & 1568 & 296 & 18 \\
\hline HSSC & $\mathrm{C} 50$ & \multicolumn{2}{|c|}{1000} & \multicolumn{2}{|c|}{2080} & 1460 & 286 & 18.2 \\
\hline concrete & designlevel & OPA & $\begin{array}{l}\text { mineral } \\
\text { powder }\end{array}$ & fly ash & gravel & sand & water & $\begin{array}{l}\text { water } \\
\text { reducer }\end{array}$ \\
\hline HCEM & $\mathrm{C} 50$ & 720 & 140 & 140 & 2080 & 1460 & 286 & 18.2 \\
\hline \multicolumn{9}{|c|}{ TABLE 3 MIX PROPORTION OF THEPASTE(WT, \%) } \\
\hline paste & OPA & & $\mathrm{SSC}$ & & $\begin{array}{l}\text { ineral } \\
\text { owder }\end{array}$ & $\begin{array}{l}\text { fly } \\
\text { ash }\end{array}$ & water & $\begin{array}{l}\text { water } \\
\text { reducer }\end{array}$ \\
\hline $\mathrm{SSC}$ & - & & 100 & & 80 & & 28.6 & 1.82 \\
\hline CEM & 72 & & - & & 14 & 14 & 28.6 & 1.82 \\
\hline
\end{tabular}

\section{Results and Discussion}

\subsection{Physical properties}

Table 4 shows the real unit weight of the three kinds of concrete mix proportion which can be used as working mix proportion has notconsistentlyexceeded $5 \%$ in designunit weight. The slump and the extension of the three concrete which has good flowabilitycomplywiththedesignrequirement. The flowability of HSSC is better than LSSC, which shows that low-grade SSC concretewith good Working performanceis easier to be prepared. Compared with HSSC and HCEM which have the same grade, the flowability of HSSC is better than that of HCEM. The flowability of the three concrete will lost after two hours stewing but has different loss rate. The loss rate is during $10 \%-20 \%$ which is not high with the highest rate of $21.5 \%$ and the lowest rate of $11.9 \%$, which shows the three concrete can keep the flowability form losing well. HCEM shows the lowest loss rate, which shows 
that the flowability loss rate of SSC concrete is a little higher than OPA concrte.

TABLE 4 PHYSICAL PROPERTIES OF DIFFERENT CONCRETE

\begin{tabular}{|c|c|c|c|c|c|c|c|c|}
\hline $\begin{array}{l}\mathrm{N} \\
\mathrm{O} .\end{array}$ & $\begin{array}{c}\text { designun } \\
\text { it weight } \\
\left(\mathrm{kg} / \mathrm{m}^{3}\right)\end{array}$ & $\begin{array}{c}\text { real unit } \\
\text { weight } \\
\left(\mathrm{kg} / \mathrm{m}^{3}\right)\end{array}$ & $\begin{array}{c}\mathrm{slu} \\
\mathrm{mp} \\
(\mathrm{mm} \\
)\end{array}$ & $\begin{array}{l}\text { extens } \\
\text { ion } \\
(\mathrm{mm})\end{array}$ & $\begin{array}{c}\text { slumpaft } \\
\text { er } \\
2 \text { hours( } \\
\text { mm) }\end{array}$ & $\begin{array}{c}\text { slump } \\
\text { loss } \\
\text { rate( } \\
\%) \\
\end{array}$ & $\begin{array}{c}\text { extension } \\
\text { after } \\
\text { 2hours(mm } \\
\text { ) }\end{array}$ & $\begin{array}{l}\text { extensi } \\
\text { on loss } \\
\operatorname{rate}(\%)\end{array}$ \\
\hline LSSC & 2370 & 2405 & 230 & 650 & 190 & 17.4 & 510 & 21.5 \\
\hline $\begin{array}{c}\text { HSS } \\
\text { C }\end{array}$ & 2460 & 2480 & 220 & 570 & 180 & 18.2 & 460 & 19.3 \\
\hline $\begin{array}{l}\mathrm{HCE} \\
\mathrm{M}\end{array}$ & 2470 & 2475 & 210 & 510 & 185 & 11.9 & 430 & 15.7 \\
\hline
\end{tabular}

\subsection{Compressive strength}

Fig 1 shows the compressive of the three concrete reach the design requests. The curing condition has little effect on the compressive of the three concrete. Under the standard curing condition with critical temperature, which guarantees the temperatureandhumidityneeds of cement and avoids cracks, the compressive strength is a little higher than that under room condition. It shows sufficienthumidity and suitable temperature are also important factors for strength development of SSC system. The compressive strength is increasing with time. Fig 1 shows the slope of the line is decreasing with time, which shows the increasing rate of compressive strength reduces. The reason is thatwith the cement hydration and hydrated produces increasing the further hydration of cement will be prevented, which accords with the chemicalreactionrule ${ }^{[8]}$. Compared to HCEM, the compressive strength of HSSC is lower than that of HCEM. While the increasing rate of HSSC strength is higher than that of HCEM at the later age and the strength of SSC at one year is only $3-4 \mathrm{MPa}$ lower than that of HCEM. differencewhich shows the potential capacity of SSC system. It may be because the main material of SSC is mineral powder whose activity will take place and contribute strength at the later age.

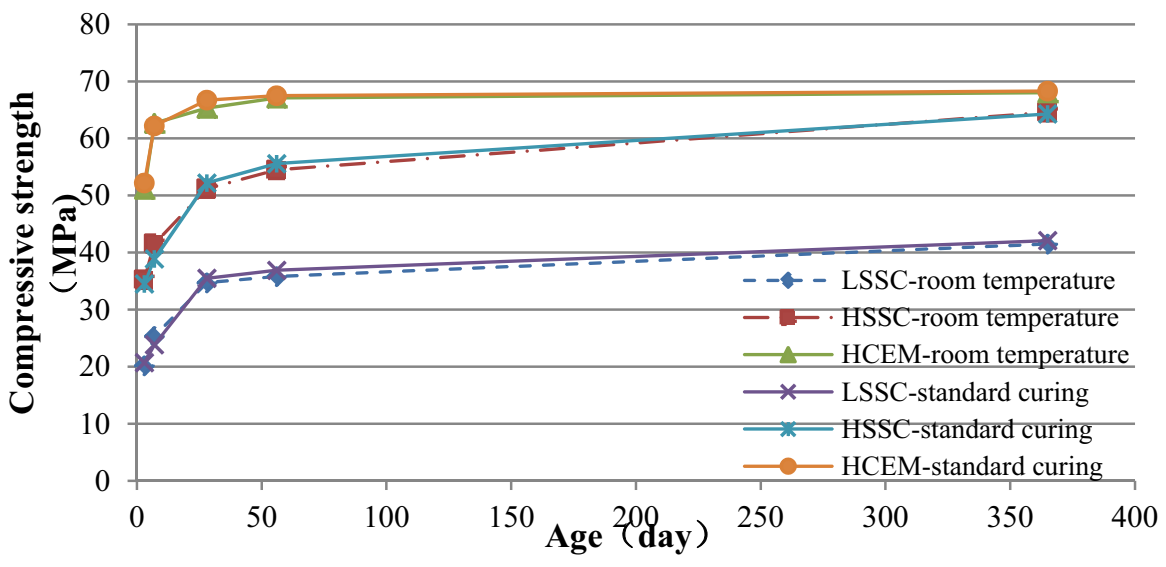

Fig 1 Compressive strength of different samples

\subsection{Temperature riseofhydration}

Fig 2 shows the final temperature rise of the three concrete. All samples show similarcurves, which demonstrates that SSC has the similar hydration process. Temperature riseofhydrationfirst increases sharply to a peak value and then decreases with time, which is a serious period for concrete cracking caused by temperature rise of hydration ${ }^{[9]}$. Contrary to 
HCEM, the temperature rise of HSSC is far lower. The temperature rise peak of HCEM is $78^{\circ} \mathrm{C}$ while that of $\mathrm{HSSC}$ is $52.5^{\circ} \mathrm{C}$. The temperature risingprocess of SSC is also much slow and the heatofhydration will be reduced much.Because the slow hydration of SSC make the temperature rise curvemoresmooth and reduces the whole hydration heat.So the use of SSC has great advantage in mass concrete to prevent the temperature cracks from arising. The temperature rise of LSSC is lower than that of HSSC which is caused by the less content of cementitious material.

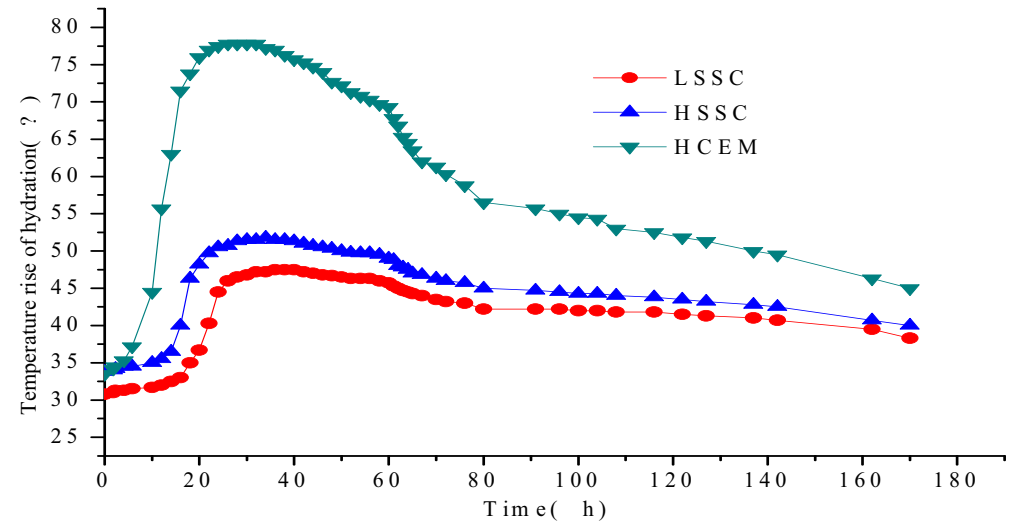

Fig 2 Temperature rise of hydration of different samples

\subsection{SEM}

Fig 3 and Fig 4 shows the SEM of LSSC at 28 days and one year. The main hydration products are flaky and a little fibrous calcium silicate hydrate (C-S-H) and short cylindrical or needle-like ettringite, which is much different with the OPA system with much $\mathrm{Ca}(\mathrm{OH})_{2}$ produced. C-S-H which is flaky structure and scale-like shape ${ }^{[10]}$ connects with each other, stick to the unhydrated particles toform the mesh structure and eventually constitute a skeletonsystem $^{[11]}$. And there are some little pores among each flaky C-S-H. According to Taylor $^{[12-13]}$, the C-S-H produced in SSC system is main C-S-H( II ) whose size is deteumined bysilicon-calcium ratio. When the size is small, the pores will increase caused by the increase of the overlap degree, which is bad for the system. Ettringite whose production is much little can be found under some local position.It can be seen that ettringite and C-S-Hgeneratedcontinuouslyfill in some cracks and pores which will improve the properties of the system.

Contrary Fig3a to Fig 4a, the scale size of C-S-H at one year is larger than that at 28 days, which is good to the system and verifies the results of compressive strength testing. It may be because the silicon-calcium ratio of C-S-H changed when C-S-H with low silicon-calcium ratio reacts with silicon to form high silicon-calcium ratio C-S-H. Ettringite can be hardly found at one year which may be transformed 


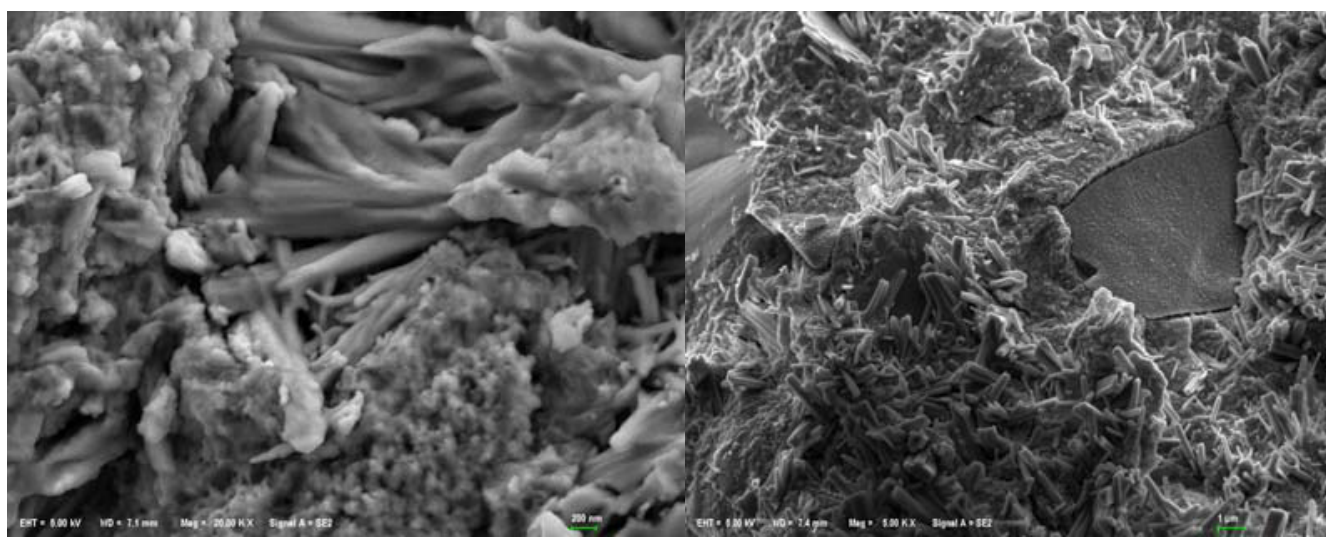

(a)

(b)

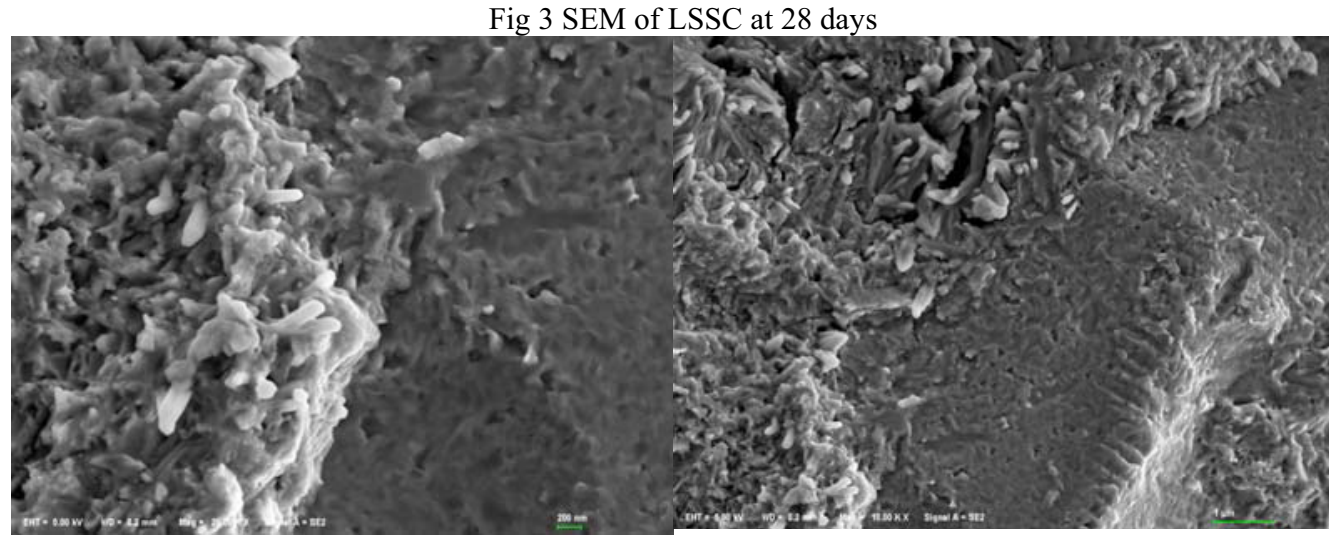

(a)

(b)

Fig4 SEM of LSSC at one year

\section{Conclusions}

(1) The slump and the extension of SSC concrete which has good flowabilitycomplywiththedesignrequirement. The flowability of HSSC is better than LSSC. The flowability of HSSC is better than that of HCEM which have the same strength grade. The flowabilityloss rate is during $10 \%-20 \%$, which shows SSC concrete can keep the flowability form losing well. Flowability loss rate of SSC concrete is a little higher than OPA concrete.

(2) Compressive strengthcured under standard condition is a little higher than that under room condition, which shows sufficienthumidity and suitable temperature are also important factors for strength development of SSC system. The compressive strength is increasing with timeand the increasing rate of compressive strength reduces. Compressive strength of SSC system is lower than that of OPA system. While the increasing rate of SSC strength is higher at the later age and the strength of HSSC at one year is only $3-4 \mathrm{MPa}$ lower than that of HCEM.

(3) Temperature riseof SSC concrete hydration first increases sharply to a peak value and then decreases with time. Contrary to HCEM, the temperature rise of HSSC is far lower. The temperature rise peak of HCEM is $78^{\circ} \mathrm{C}$ while that of HSSC is $52.5^{\circ} \mathrm{C}$. The temperature risingprocess of SSC is much slow and the heatofhydration will be reduced much So the use of SSC has great advantage in mass concrete to prevent the temperature 
cracks from arising. The temperature rise of LSSC is lower than that of HSSC which is caused by the less content of cementitiousmaterial.

(4) The main hydration products are scale-like C-S-H(II) and short cylindrical or needle-like ettringite, which is much different with the OPA system with much $\mathrm{Ca}(\mathrm{OH})_{2}$ produced. The system becomes denser with time as the silicon-calcium ratio of C-S-H changes and the scale size of C-S-H becomes larger.

\section{References}

1. TMatschei,EBellmann,J.Stirk.Hydration behaviour of sulphate-activated slagcements [J]. Advancesin Cement Research, 2005,17(4):167-178.

2. F. Puertas, M. Palacios, A. Gil-Maroto, T. Vázquez. Alkali-aggregate behaviour of alkali-activated slag mortars: Effect of aggregate type [J]. Cement \& Concrete Composites, 31 (2009): 277-28.

3. T. Bakharev, J.G. Sanjayan, Y.B.Cheng. Resistanceof alkali-activated slag concrete to alkaliaggregate reaction [J].Cement and Concrete Research, 31 (2001): 331 -334.

4. Erdem E, Olmez H. The Mechanical Properties of Supersulfated CementContainingPhosphogysum [J].Cement and Concrete Research,1993, 23 (1):115-121.

5. WeiguoShen, Minggai Zhou Jin Cha, Qinglin Zhao.Research on the Proportion Design of Phosphogypsum ModificationLime Fly-ash Road Base Material [J].Journal of Wuhan Universityof Technology. 2005, 27(10):19-22.

6. WeiguoShen, Minggai Zhou Jin Cha, Qinglin Zhao. StudyonthePropertionDesignof Lime-Flyash Road Base Material by Phosphogypsum [J]. Fly Ash Comprehensive Utilization, 2004(3):13-15.

7. Edward GNawy,P.E.,CEng.Concrete construction engineering handbook.. 2008.

8. Xiao J, Li L, Shen L, et al. Compressive behaviour of recycled aggregate concrete under impact loading[J]. Cement \& Concrete Research, 2015, 71:46-55.

9. Wu Yong, Luna Ronaldo. Numerical implementation of temperature and creep in mass concrete[J]. Finite Elements in Analysis and Design, 2001, 37(2):97-106.

10. Zhao Xiaogang. Synthesis of calcium silicate hydrate and its composition, structure and morpjolocy[D].Wuhan University of Technology, 2010.

11. Shuhua Liu, GuoshuaiXie, Shuwang. Effect of curing temperature on hydration properties of wasteglass powder in cement-based materials[J]. J Therm Anal Calorim, 2015( 119):47-55.

12. H.F.W. Taylor, Proposed structure for calcium silicate hydrate gel[J]. J.Am. Ceram. Soc. , 1986,69 (6):464-467.

13. Dolado J S, Griebel M, Hamaekers J, et al. The nano-branched structure of cementitious calcium-silicate-hydrate gel[J]. Journal of Materials Chemistry, 2011, 12(12):4445-4449. 